\title{
PESQUISA DE LOS ESTADIOS INICIALES DEL CARCINOMA CERVICAL
}

\author{
Doctor Guillermo di Paola (Buenos Aires)
}

Es indudable que en el estado actual de los recursos terapéuticos el tratamiento del carcinoma cervical ha alcanzado un nivel de eficiencia que difícilmente podrá ser superado mientras no se modifique la calidad del material de enfermas que llega a la consulta. Al decir esto deseo referirme a los resultados logrados en los Centros o Institutos más perfeccionados, en países con mayor progreso sanitario, en los que la proporción absoluta de curaciones llegan al $42 \%$. Pero si este porcentaje absoluto es necesario establecerlo para apreciar la real efectividad del tratamiento y la calidad de las enfermas atendidas, los porcentajes relativos de curación correspondientes a cada estadio evolutivo demuestran claramente las diferencias obtenidas según el grado de propagación, pues del 70 al $90 \%$ del 1er. estadio se pasa al $0 \%$ y $7 \%$ para el estadio IV. El mayor esfuerzo debe dirigirse a lograr el diagnóstico precoz que permitirá lenta pero seguramente mejorar los porcentajes absolutos de curación a medida que los primeros estadios predominen en las estadísticas.

La actualización del antiguo concepto del carcinoma intraepitelial o epitelio atípico no invasor (EANI), como preferimos llamarlo, significó un progreso notable en el tratamiento, ya que se demostró que esta lesión no sólo acompaña frecuentemente al carcinoma cervical, como se sabía hace tiempo, sino que muy a menudo lo precede. Si es posible diagnosticarlo en esta última circunstancia, cuando aún no hay invasión, pero tampoco se manifiesta por síntomas ni signos, puede obtenerse la curación casi en el $100 \%$ de los casos. Este es el fundamento patológico y clínico de la pesquisa del EANI, que obliga a no escatimar esfuerzos para organizarla de un modo eficiente, cuyos resultados deseamos comunicar en base a la experiencia recogida en la I Cátedra de Ginecología de Buenos Aires.

Iniciamos en 1957 un programa de pesquisa coordinando la labor de los departamentos de colposcopia, citodiagnóstico y patología para examinar, mediante estos 3 métodos, a todas las mujeres con lesiones cervicales que concurrieron al Consultorio Externo, es decir, en casos seleccionados. A fines de 1958 se creó el Centro de Citodiagnóstico, y desde 1959 se inició la verdadera pesquisa, es decir, se extendió la inves- 
tigación citológica a todas las internadas y luego a todas las mujeres que acudían al ambulatorio, tuvieran o no lesiones cervicales. En 1961 se amplió esta sistemática a las enfermas internadas por cualquier motivo en los servicios

\section{A) Epitelios} anómalos

B) Epitelios inquietos

\section{C) Epitelios} atípicos
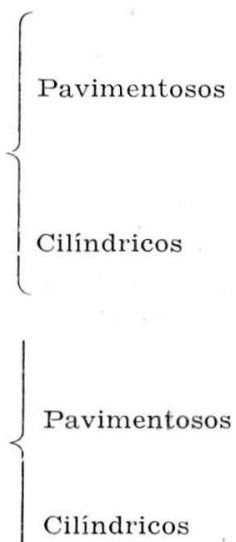

de medicina; se ha totalizado así 8342 mujeres chequeadas hasta el 31 de mayo del corriente año. Resulta de interés considerar los diagnósticos de EANI efectuados en el mismo ambiente antes de iniciar estas investigaciones para evidenciar la importancia de las mismas y su eficacia, ya que el personal técnico actuante en el examen clínico y patológico era siempre el mismo y altamente especializado.

TABLA I

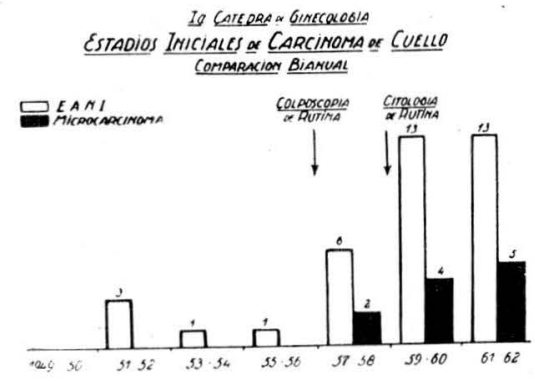

Antes de entrar a considerar los resultados conseguidos expondremos la nomenclatura y clasificación de las alteraciones del epitelio cervical según Sammartino, que seguimos en nuestro trabajo:
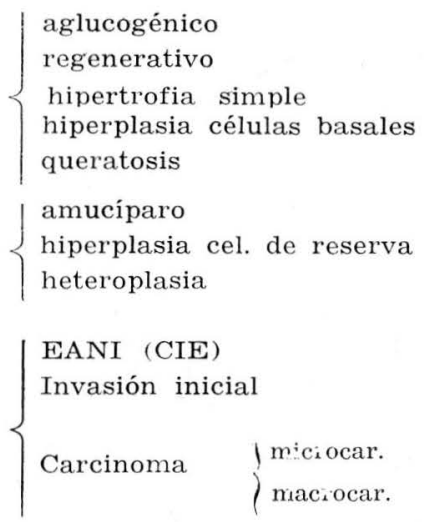

El EANI es la denominasión propuesta por Held, en lugar de la más difundida de C. I. E. o carcinoma in situ, que nosotros preferimos y adoptamos, pues la sola mención de la palabra carcinoma impresiona profundamente a los médicos y puede inducirlos a errores terapéuticos. Histológicamente se caracteriza por intensa basofilia, núcleos hipercromáticos, mitosis atípicas, ausencia de puentes y espacios intercelulares, disposición irregular de los ejes celulares y falta de estratificación; en síntesis, atipia citológica y estructural, pero sin invasión.

Cuando se habla de pesquisa significa examinar mujeres aparentemente sanas para seleccionar aquellas que presentan signos de malignidad con el método detector utilizado, en las que ulteriormente se completa el diagnóstico con la aplicación de otros procedimien- 
tos localizadores. Este programa no es estricto en un Servicio de Ginecología, pues la gran mayoría de las mujeres que concurren padecen de algún trastorno en el aparato genital, aunque no necesariamente tienen lesiones cervicales; esta falla la hemos tratado de corregir parcialmente ampliando la investigación a las internadas en Salas de Medicina. De cualquier modo los casos descubiertos en la consulta ginecológica eran absolutamente insospechados desde el punto de vista clínico, a pesar de haber sido examinados por personal médico bien entrenado y de experiencia, y cada vez estamos más convencidos que el simple examen visual, aun complementado con la lugolización, es insuficiente para descubrir los estadios iniciales del carcinoma cervical. Además del EANI fueron descubiertos, al efectuar la pesquisa, algunos carcinomas iniciales y microcarcinomas que igualmente se caracterizan por la ausencia o pobreza de síntomas y signos clínicos, y más aún, algunos carcinomas genuinos que habían pasado clínicamente desapercibidos. Los métodos utilizados fueron tres: $1{ }^{\circ}$ Citodiagnóstico, $2^{\circ} \mathrm{Col}-$ poscopia, y 39 Biopsia en el orden señalado.

La citología exfoliativa fue utilizada como método detector, habiendo sido efectuada en 8342 mujeres hasta el 31$\mathrm{V}-1962$. El material fue extraído directamente del cérvix con espátula de madera en el $90 \%$ de los casos, previa colocación de espéculo, siendo ésta otra ventaja de la pesquisa realizada en un Servicio de Ginecología, ya que este método se ha demostrado más eficaz que la simple toma vaginal. En el ma- nipuleo de los extendidos se siguieron la técnica y clasificación propuestas por Papanicolaou. La organización adoptada para examinar tan considerable material consiste en la selección escalonada de los extendidos en forma piramidal por personal técnico cada vez más competente hasta arribar al diagnóstico citológico definitivo. La recolección del material fue facilitada por la confección de pequeñas cajas que contenían todos los elementos necesarios (portas, clips, fijador, pipetas), que distribuímos en los consultorios para ser utilizadas por los médicos antes de proceder al examen manual. Es imposible pretender que todos los médicos sean peritos en colposcopia, o que se efectúen biopsias a granel por la tarea abrumadora que ello supondría para el patólogo, y es evidente que anteponiendo la citología como método de pesquisa se consigue una buena selección de enfermas y la concentración de todo el material en el laboratorio donde actúa el equipo en la forma ya expresada.

Conviene hacer notar que en citología carecen de valor decisivo los extendidos positivos o sospechosos que no puedan confirmarse histológicamente, ya que el informe citológico es sólo un diagnóstico provisorio que requiere comprobación antes de iniciar la terapéutica correspondiente. El diagnóstico definitivo o "legal" del carcinoma depende, hoy como ayer, de la biopsia.

Desde 1957 hasta el 31-V-1962 fueron hallados 32 EANI y 11 microcarcinomas, pero a los efectos de considerar los resultados del citodiagnóstico no consideramos 6 EANI y 2 microcarcinomas que fueron diagnosticados en 
1957-58, es decir, cuando aquél se utilizaba en casos seleccionados y no en forma de pesquisa. De modo pues que sobre 8342 mujeres investigadas de 1959 en adelante tuvimos 26 EANI y 9 microcarcinomas:

TABLA II

Io CATrosa or Gimecologia

Pesquisa Citologica en 8342 Mujeres Madzo 1959 - Mavo 1962

\begin{tabular}{lcc} 
LESION DESCUBIERTA & NO. & DOR 1000 \\
\hline E.A.M.I. & 21 & 2.5 \\
MICROCARCINOMA & 9 & 1 \\
\hline TOTAL & 30 & 3.5
\end{tabular}

Esto significa que en el $19,2 \%$ la citología dio un resultado falso negativo cuando la lesión era EANI. Con el microcarcinoma no tuvimos falsos negativos. Podemos decir entonces que en las 8342 mujeres investigadas mediante la citología se descubrieron 21 EANI, descontando los 5 falsos negativos, y 9 microcarcinomas, alcanzando entonces la proporción de casos detectados al 3,5\% o (Tabla II).

Los falsos negativos constituyen indudablemente la "bête noire" del citodiagnóstico, pues si se trabaja exclusi- vamente con este método, las consecuencias pueden ser graves. En nuestra estadística sobre 35 casos (26 EANI y $9 \mathrm{mc}$.) el porcentaje de falsos negativos llega al 14,2\%. A este respecto es oportuno destacar que el método tiene limitaciones y está expuesto a error en los casos de lesiones muy poco extendidas y si la atipia se halla localizada a las capas profundas del epitelio o en las cavidades glandulares. Además, siempre pueden existir las fallas comunes atribuídas a la mayor o menor $\because \ell$ periencia del personal técnico y a deficiencias en la organización, lo que se evidencia en el porcentaje de extendidos sospechosos clase III, que cuando el equipo trabaja bien debe quedar reducido a cifras cada vez más bajas.

La colposcopia es el método localizador, es decir, determina la ubicación del epitelio atípico, siempre que esté situado en el exocérvix o en el tercio inferior del canal endocervical, y permite así efectuar la microbiopsia selectiva evitando el serio riesgo de biopsiar zonas vecinas sin lesiones. Queda, pues, fuera de sus posibilidades diagnósticas las localizaciones más altas dentro del canal endocervical.

La técnica es aparentemente sencilla, pero se requieren aparatos de muy buena calidad y una amplia experiencia

TABLA III

26 EANI

9 microcar-
Extendidos positivos (IV)

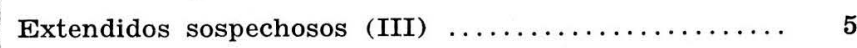

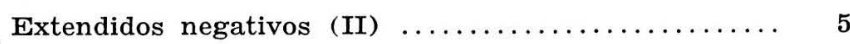

Extendidos positivos (IV y V) $\ldots \ldots \ldots \ldots \ldots \ldots \ldots \ldots$

\{

Extendidos negativos (II)

Extendidos sospechosos (III)
16 8 
para aprovechar sus grandes posibilidades. Así como cuando nos referimos al citodiagnóstico decíamos que la eficiencia del equipo se traduce en el número cada vez menor de extendidos clase III o sospechosos, en colposcopia la eficiencia se aprecia a través del porcentaje de biopsias efectuadas y por los hallazgos de las mismas, pues la correcta interpretación colposcópica de las lesiones observadas permite reducir aquellas cada vez más. Las imágenes fisiológicas o benignas (zona de trasformación, ectopias, cervicitis) no requieren confirmación histológica que sólo es necesaria en las imágenes anómalas (mosaico, leucoplasia, base, zona de trasformación anómala, base papilar). Aun dentro de estas últimas el colposcopista experimentado puede hallar algunos indicios que refuerzan la sospecha de atipia como son: hiperplasia vascular, vasos anómalos, mosaicos de campos irregulares y coincidencias o superposición de imágenes anómalas. En el Consultorio de Patología Cervical de la 1ạ Cátedra de Ginecología sobre 500 colposcopias efectuadas en 1960 se juzgó necesario realizar 80 biopsias $(16 \%)$, en 14 de las cuales se descubrió un epitelio atípico, lo que representa un resultado positivo cada 5,7 biopsias. En 2.200 colposcopias efectuadas de 1957 a 1961 se han realizado 411 biopsias (18,6\%) que han permitido diagnosticar 29 EANI, 11 microcarcinomas y 12 carcinomas genuinos clínicamente insospechados (ver Tabla 4).

Igualmente hemos comprobado que cuando el personal médico especializado que realiza las colposcopias es modificado, el cambio se refleja tanto en
TABLA IV

\begin{tabular}{|c|c|c|c|}
\hline & \begin{tabular}{|l}
$N^{\circ} D E$ \\
CASOS
\end{tabular} & $\begin{array}{l}\text { INCIDENC } \\
2200 \text { EXAMENES } \\
\text { COLPOSCOPICO- } \\
\text { CITOLOGICOS } \\
\end{array}$ & $\begin{array}{l}\text { IA SOBRE } \\
\text { L1: BIOPSIAS } \\
\text { REALIZADAS } \\
18,5 \%\end{array}$ \\
\hline $\begin{array}{l}\text { CARCINOMA } \\
\text { INTRAEPITELIAL }\end{array}$ & 29 & $1,3 \%$ & $7 \%$ \\
\hline $\begin{array}{c}\text { CARCINOMA } \\
\text { DE INVASION DUDO- } \\
\text { SA O INCIPIENTE } \\
\end{array}$ & 11 & $0.5 \%$ & $2.6 \%$ \\
\hline $\begin{array}{c}\text { CARCINOMA } \\
\text { INVASOR CLINICAMEN- } \\
\text { IE NO SOSPECHADO } \\
\end{array}$ & 12 & $0.5 \%$ & $2.9 \%$ \\
\hline TOTAL & 52 & $2.3 \%$ & $12.6 \%$ \\
\hline
\end{tabular}

la proporción de biopsias como en el número de resultados positivos.

La coexistencia de imágenes colposcópicas anómalas constituye una seria presunción de lesiones atípicas, las que aun cuando no se revelan en la biopsia selectiva que en estos casos debe ser repetida, pueden estar localizadas en el canal endocervical. La colposcopia debe ser ampliada a los "fornix" vaginales cuando se diagnostica un EANI o microcarcinoma, para investigar la posible propagación vaginal de la lesión, siendo en este sentido mucho más efectiva que la lugolización.

La colpofotografía ha sido un complemento de gran utilidad para la mayor eficiencia de la colposcopia. En efecto, mediante las fotografías es posible precisar y fijar los detalles visuales de las lesiones observadas, trasmitir la experiencia personal con mayor facilidad, y sobre todo coordinar con el patólogo la selección y ubicación de las biopsias efectuadas o a realizar.

Sobre un total de 2.200 mujeres examinadas colposcópicamente y 40 estadios iniciales descubiertos hemos tenido 6 resultados falsos negativos, es decir, el $15 \%$. Pero de estos 6 casos en 4 la 
localización del carcinoma era endocervical, circunstancia en que la citología debe ser considerada lógicamente más efectiva, como ocurrió en las 4 enfermas que presentaron todas un extendido clase IV:

Corresponde repetir que como la citología, la colposcopia no autoriza a asegurar el diagnóstico de atipia sino solo a sospecharlo, siendo indispensable la confirmación histológica. En resumen, la colposcopia, actuando como puesta otorga el máximo rendimiento. El $15 \%$ de falsos negativos de la colposcopia y el $14,2 \%$ de falsos negativos comprobados con la citología se reducen en nuestra estadística al $5 \%$ si se consideran simultáneamente los resultados de los dos métodos. Con fines de comparación hemos agrupado en la tabla $\mathrm{V}$ los falsos negativos en que pueden incurrir ambos procedimientos de acuerdo a las estadísticas de reputados Centros:

TABLA V

INCIDENCIAS DE FALSOS NEGATIVOS

\begin{tabular}{|c|c|c|}
\hline Autor & $\begin{array}{c}\text { Colposcopia } \\
\%\end{array}$ & $\begin{array}{c}\text { Citología } \\
\%\end{array}$ \\
\hline Burghard y Bajardi $\ldots \ldots \ldots \ldots \ldots \ldots$ & 24 & 15,6 \\
\hline Cramer $\ldots \ldots \ldots \ldots \ldots \ldots \ldots \ldots \ldots$ & 6,7 & 8,9 \\
\hline Zinser $\ldots \ldots \ldots \ldots \ldots \ldots \ldots \ldots \ldots \ldots \ldots \ldots$ & 35 & 6,8 \\
\hline Limburg $\ldots \ldots \ldots \ldots \ldots \ldots \ldots \ldots$ & 3 & 10 \\
\hline Held $\ldots \ldots \ldots \ldots \ldots \ldots \ldots \ldots \ldots$ & 8 & 13 \\
\hline Di Paola, Vásquez y Peluffo $\ldots \ldots \ldots \ldots$ & 15 & 14,2 \\
\hline
\end{tabular}

método localizador, permite: a) efectuar biopsias selectivas evitando el grave riesgo de biopsiar zonas vecinas que pueden-ser normales;

b) reducir progresivamente el número de biopsias innecesarias;

c) control periódico de lesiones de naturaleza no bien definida.

Se ha pretendido establecer un paralelo entre los resultados conseguidos con la citología y colposcopia, pero de acuerdo con las consideraciones ya expuestas y la amplia experiencia recogida, puede decirse que los dos métodos tienen sus limitaciones y que el empleo simultáneo y sistemático de ambos en la forma ex-
El resultado positivo de la pesquisa citológica y/o de la exploración colposcópica plantea el problema de la confirmación diagnóstica que debe hacerse con la histología, es decir, la biopsia. Es oportuno recordar que hasta no hace mucho tiempo la biopsia se efectuaba sólo para confirmar o desechar la sospecha de una lesión cervical palpable o visible, en tanto que ahora con ella se investigan también lesiones inaparentes a los recursos clínicos clásicos, inspección y palpación, circunstancia que ha obligado a reconsiderar su concepto y técnica.

La biopsia debe ser una maniobra simple, sin complicaciones para poder 
ser efectuada en el consultorio inmediatamente después de la colposcopia. Conviene pues, hacer tomas pequeñas con pinzas-sacabocados apropiadas entre las que preferimos las Schubert o Hillemans, que permiten realizarla sin dolor ni hemorragia, aun en las mujeres grávidas.

La efectividad de la biopsia depende de su localización, ya que si no se hace en la zona debida, como lo dice Novak, el informe del patólogo "es peor que inútil" dando una falsa sensación de seguridad. La biopsia selectiva bajo el control colposcópico confiere a la maniobra la máxima precisión, pues permite localizar el área sospechosa y realizar o repetir tomas todas las veces que se considere necesario. Parece obvio hacer resaitar la gran seguridad de esta sistemática frente a las biopsias hechas al azar o en los cuatro puntos cardinales, o aún con la precaria ayuda de la lugolización, procedimientos éstos que si pueden explicarse en algunas circunstancias por razones ambientales, no las consideramos adecuadas en Centros altamente especializados.

La biopsia colposcópica o al acecho debe efectuarse cuando se descubren imágenes anómalas, es decir, leucoplasias, mosaicos, bases papilares, vascularización anormal, realizándose generalmente 2 o 3 tomas sobre los bordes de la lesión. En cambio, en el caso de citología positiva y colposcopia negativa debe recurrirse al legrado-biopsia endocervical, que también realizamos cuando a pesar de existir imágenes colposcópicas anómalas las biopsias exocervicales resultan negativas.
En el esquema siguiente sintetizamos la sistemática que seguimos después de conocer el informe histológice de la biopsia efectuada en las circunstancias antecitadas:

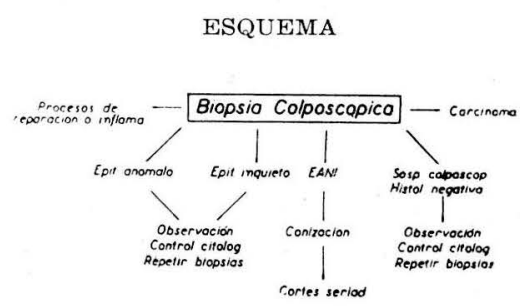

La comprobación de epitelios anómalos, con alteraciones estructurales simples (aglucogénico, queratósico, hiperplasia de células basales, regenerativo) pero que se desvían de los procesos comunes de reparación o inflamación, obliga a mantener a la enferma en observación periódica con control citológico y repetición de biopsias.

El epitelio inquieto significa que el patólogo no se ha sentido capaz de asegurar la naturaleza maligna, pero que tiene dudas, por lo tanto conviene proseguir la vigilancia periódica con mayor cuidado que en el caso anterior.

El hallazgo de un EANI o CIE significa el éxito de la pesquisa y la posible curación de la paciente, pues se impide la evolución progresiva hacia el carcinoma evolutivo. Pero es necesario tener en cuenta la frecuente coincidencia del EANI con un carcinoma en otras zonas del exo o endocérvix, y por lo tanto se halla formalmente indicado en este caso efectuar una conización amplia seguida de un minucioso examen 
histológico mediante cortes seriados o semiseriados para eliminar esa posibilidad. El ideal de los cortes seriados no se halla al alcance de muchos laboratorios, pero los semiseriados son posibles y bastante seguros. Nosotros procedemos como se indica en la figura 1, obteniendo 16 cortes, que son numerados y estudiados por separado. Solamente si en este prolijo estudio no se halla un carcinoma, puede confirmarse el diagnóstico definitivo de EANI con las deducciones terapéuticas consiguientes.

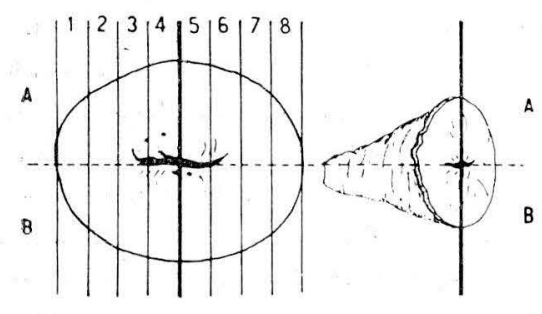

Figura 1. Sistematización de los cortes semiseriados en la conización.

La biopsia o legrado endocervical, que ya no es colposcópica, debe efectuarse obligatoriamente cuando con extendidos positivos la colposcopia no revela imágenes anómalas. Si el informe histológico es positivo, EANI, se debe hacer igualmente una conización para eliminar la posible coincidencia con un carcinoma y determinar al mismo tiempo si la lesión ha sido sobrepasada por la sección quirúrgica efectuada.
Como síntesis de la importancia que tiene la biopsia como método diagnosticador deseamos destacar que la opinión del patólogo es de fundamental importancia, pues sólo él puede ilustrarnos acerca de la agresividad o malignidad que atribuye a la lesión atípica del epitelio. En este sentido queremos significar que los éxitos de la pesquisa de los estadios iniciales del carcinoma cervical corresponden al trabajo coordinado de todo un equipo, en el que todos deben sentirse igualmente responsables de la delicada tarea que desempeñan.

TABLA VI

\begin{tabular}{|c|c|c|c|c|}
\hline AUIOR & $\Delta \hat{N}-S$ & $\begin{array}{c}\text { CAFCINOMAS } \\
\text { NTRAEATLLIA. }\end{array}$ & $\begin{array}{l}\text { CARCINDMA } \\
\text { INVASTR }\end{array}$ & $\%$ \\
\hline WWIER ${ }_{\text {BERLIN }}^{5}$ & 1954.56 & 40 & 669 & 6 \\
\hline 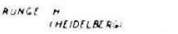 & $1955 \cdot 56$ & 18 & 276 & 6,5 \\
\hline DOOFALEIN, Jesw & 1955 & 1 & 219 & 0,4 \\
\hline 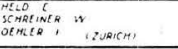 & $1952-53$ & 27 & 145 & 18,6 \\
\hline 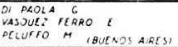 & $1957-61$ & 29 & 263 & 11 \\
\hline
\end{tabular}

Para terminar y como síntesis de la labor realizada deseo hacer notar el número progresivamente creciente de EANI que han sido descubiertos en nuestra Clínica desde 1957 en adelante, alcanzando su proporción frente a los carcinomas asistidos en el mismo lapso al $11 \%$, según puede verse en la tabla VI. Simultáneamente fueron hallados 11 microcarcinomas, con lo que se totalizan 43 casos de estadios iniciales. 